OPEN ACCESS

Edited by:

Cheng Guo,

Zhejiang University, China

Reviewed by:

Quanqing Zhang,

University of California, United States

Ge Ma,

Sinopec Research Institute of Safety

Engineering, China

*Correspondence:

Ling Ling

lingling@nbu.edu.cn

Shaoning $Y u$

yushaoning@nbu.edu.cn

Tao Pan

2311318@zju.edu.cn

${ }^{\dagger}$ These authors contributed equally to this work

Specialty section:

This article was submitted to Analytical Chemistry,

a section of the journal

Frontiers in Chemistry

Received: 26 February 2021

Accepted: 19 April 2021

Published: 30 April 2021

Citation:

Ying J, Gao W, Huang D, Ding C,

Ling L, Pan T and Yu S (2021) Application of MALDI-TOFMS Profiling Coupled With Functionalized Magnetic Enrichment for Rapid Identification of

Pathogens in a Patient With

Open Fracture.

Front. Chem. 9:672744.

doi: 10.3389/fchem.2021.672744

\section{Application of MALDI-TOF MS Profiling Coupled With Functionalized Magnetic Enrichment for Rapid Identification of Pathogens in a Patient With Open Fracture}

\author{
Jichong Ying ${ }^{1 \dagger}$, Wenjing Gao ${ }^{2 \dagger}$, Dichao Huang ${ }^{1}$, Chuanfan Ding ${ }^{2}$, Ling Ling ${ }^{2 *}$, Tao Pan $^{3 *}$ and \\ Shaoning $\mathrm{Yu}^{2 *}$
}

${ }^{1}$ Ningbo No. 6 Hospital, Ningbo, China, ${ }^{2}$ Key Laboratory of Advanced Mass Spectrometry and Molecular Analysis of Zhejiang Province, Institute of Mass Spectrometry, School of Material Science and Chemical Engineering, Ningbo University, Ningbo, China, ${ }^{3}$ Department of Breast Surgery and Oncology, The Second Affiliated Hospital, Zhejiang University School of Medicine, Hangzhou, China

Posttraumatic infections can occur in orthopedic trauma patients, especially in open fractures. Rapid and accurate identification of pathogens in orthopedic trauma is important for clinical diagnosis and antimicrobial treatment. Matrix-assisted laser desorption/ionization time-of-flight mass spectrometry (MALDI-TOF MS) has been successfully used for first-line identification of pathogens grown on culture plates. However, for direct analysis of liquid clinical specimens, pre-purification of the sample is necessary. Herein, we investigated the feasibility of coupling FC-MBL@ $\mathrm{Fe}_{3} \mathrm{O}_{4}$ enrichment with MALDI-TOF MS profiling in the identification of pathogens in liquidcultured samples. This method is successfully used for the identification of pathogens in a patient with an open-leg fracture obtained at sea. Pathogens were enriched by Fc$\mathrm{MBL} @ \mathrm{Fe}_{3} \mathrm{O}_{4}$ from briefly pre-cultured liquid media and identified by MALDI-TOF MS. We identified an opportunistic pathogen, Vibrio alginolyticus, which is uncommon in clinical orthopedic trauma infection but exists widely in the sea. Therefore, combining FC-MBL@ $\mathrm{Fe}_{3} \mathrm{O}_{4}$ enrichment and MALDI-TOF MS profiling has great potential for direct identification of microbes in clinical samples.

Keywords: MALDI-TOF MS, orthopedic trauma infection, magnetic enrichment, pathogen identification, Vibrio alginolyticus

\section{INTRODUCTION}

Orthopedic traumas are complex and diverse. Serious wounds are always difficult to debride; especially, when complicated fractures are combined, the surgical treatment is often required (Morgenstern et al., 2018; Tuon et al., 2019). Posttraumatic infections can occur in orthopedic trauma patients when it is not treated in a timely manner or after surgical treatment (Arnold et al., 2013; Yun et al., 2016; Backes et al., 2018). Rapid identification of pathogenic bacteria in orthopedic trauma, especially open fractures, guides the clinical diagnosis and antimicrobial treatment (Yun et al., 2016; Patrulea et al., 2020). Thus, superficial wound swabs or deep fluid samples are always sent to the clinical microbiology lab for bacterial identification. 
The current standard of bacterial identification in hospitals continues to rely on culture-based biochemical testing, which may take days to complete (Varadi et al., 2017; Backes et al., 2018). Moreover, culture-based methods suffer increasing skepticism about their sensitivity and accuracy (Rhoads et al., 2012; Firoozabadi et al., 2015). Molecular methods that rely on the analysis of genomic markers, such as ribosomal RNA sequencing, have better sensitivity and accuracy for pathogen identification (Rhoads et al., 2012). However, molecular diagnostic methods have high cost and require sophisticated expertise (Woo et al., 2008; Segawa et al., 2014). In recent years, matrix-assisted laser desorption/ionization time-of-flight mass spectrometry (MALDI-TOF MS) has been introduced into clinical microbiology laboratories. Due to the specificity, speed of analysis, and low cost of consumables, MALDI-TOF MS has been widely acclaimed for clinical bacterial identification (Welker et al., 2019; Feng et al., 2020; Nomura et al., 2020; Papagiannopoulou et al., 2020). MALDI-TOF MS identification is mainly based on the MS fingerprint pattern of bacterial ribosomal proteins in the $m / z$ range of $2-20 \mathrm{kDa}$, which can be compared to the MS database to identify the bacterial genus and species (Singhal et al., 2015). MALDI-TOF MS databases with more than 4000 strains have been set up and are widely used in the identification of clinical bacteria, fungi, mycobacteria, and Nocardia (Feng et al., 2020). Nevertheless, the single colonies are always needed for this method. Clinical samples or liquid cultured samples are inoculated on solid culture plate to grow single colonies for identification by MALDI-TOF MS. For direct analysis of bacteria in liquid clinical samples, the pre-purification steps are mandatory. Since approximately $10^{5} \mathrm{CFU}$ of bacteria are needed for successful identification, direct analysis of bacteria in clinical samples seems only possible for urine samples (Zboromyrska et al., 2016). Utilizing of liquid cultures has increased the sensitivity and decreased the turn-around time of bacterial culture, especially for samples with low bacterial loads. Hence, development of pre-purification methods for liquid-cultured bacterial sample is sorely needed.

Functionalized magnetic nanoparticles (MNPs) have been developed to capture bacteria and simplify the purification processes due to its large ratio of surface area to volume, ease of operation, and good biocompatibility (Liébana et al., 2009; Cheng et al., 2016; Zhu et al., 2016; Yi et al., 2018; Nemr et al., 2019). Specific aptamers and antibodies were conjugated with MNPs to enrich certain bacteria or part of microbes from suspension (Liébana et al., 2009; Cheng et al., 2016; Zhu et al., 2016; Yi et al., 2018; Nemr et al., 2019). Mannose-binding lectin (MBL) is an important opsonin component of the lectin pathway associated with innate immunity, which can recognize and bind carbohydrates on the surfaces of different bacteria, fungi, and viruses in a calcium-dependent manner (Takahashi and Ezekowitz, 2005). Ingber et al. genetically engineered a new version of MBL by fusing the carbohydrate recognition region of MBL to the flexible neck of the Fc portion of IgG1, which conjugated with MNPs and was used to cleanse septic blood or enrich bacteria in clinical samples (Kang et al., 2014; Bicart-See et al., 2016). These studies indicated that Fc-MBL has binding capability for a wide range of microbes, which prompted us to utilize Fc-MBL@Fe $\mathrm{F}_{3}$ to enrich bacteria and combine with the MALDI-TOF MS identification.

Herein, we investigated the feasibility of the MALDI-TOF MS profiling coupled with $\mathrm{Fc}-\mathrm{MBL} @ \mathrm{Fe}_{3} \mathrm{O}_{4}$ enrichment for identification of bacteria in liquid culture media (Scheme 1). After the verification, the application of this method in real case was explored. A patient obtained an open fracture at sea and did not acquire treatment for more than $20 \mathrm{~h}$ due to diagnostic limitations. Considering that the patient was injured at sea, uncommon species of bacteria may have adhered to the wound; we attempt to use $\mathrm{Fc}-\mathrm{MBL} @ \mathrm{Fe}_{3} \mathrm{O}_{4}$ enrichment coupled with MALDI-TOF MS identification. A wound swab and fluid were short-term cultured on liquid media and analyzed by the proposed method, wherein Vibrio alginolyticus was identified. These results show that these pathogen identification procedures are more rapid than traditional methods and beneficial for clinical treatment of patients.

\section{MATERIAL AND METHODS}

\section{Patient}

A 56-year-old male patient was crushed while working on the boats, and his right calf was stressed, accompanied by skin lacerations and bleeding. He had an open wound approximately $6 \times 15 \mathrm{~cm}$ in the lower part of the right calf, and the fractured end was exposed. Because the patient was unable to acquire clinical treatment at sea, the wound was simply bandaged to stop the bleeding. After more than $20 \mathrm{~h}$, the patient was sent to the hospital and diagnosed with open comminuted fracture of the lower right tibia and fibula. This study was approved by the Ethics Committee of Ningbo No. 6 Hospital.

\section{Chemicals and Instruments}

$\alpha$-Cyano-4-hydroxycinnamic acid (CHCA), formic acid, and acetonitrile (ACN) were purchased from Merck (Darmstadt, Germany). Trifluoroacetic acid (TFA) was obtained from Shanghai Macklin Biochemical Technology Co., Ltd. (Shanghai, China). Tryptone soybean agar (TSA) and Luria-Bertani (LB) broth were purchased from Beijing Land Bridge Technology Co., Ltd (Beijing, China). The functionalized MNPs $\left(\mathrm{Fc}-\mathrm{MBL} @ \mathrm{Fe}_{3} \mathrm{O}_{4}\right)$ were synthesized as in our previous study (Sun et al., 2021). The detailed synthesis procedures and characterization results are presented in the Supporting Information.

The mass spectra for the verification of method were obtained by Autoflex max TOF/TOF mass spectrometer (Bruker Daltonics, Germany) with a pulsed Nd:YAG laser $(355 \mathrm{~nm})$ in a linear positive mode. The acceleration voltage was set at $20 \mathrm{kV}$, each spectrum was acquired by 1000 laser shots, and the laser intensity was regulated to ensure a good signal-to-noise ratio. MALDITOF MS identification was carried out using an M-Discover 100 mass spectrometer (Zhuhai Meihua Medical Technology Co., Ltd. China) in a linear positive mode with the $m / z$ range 2-20 KDa. The mass spectra were calibrated by Escherichia coli (ATCC 8739) according to the manufacturer's 


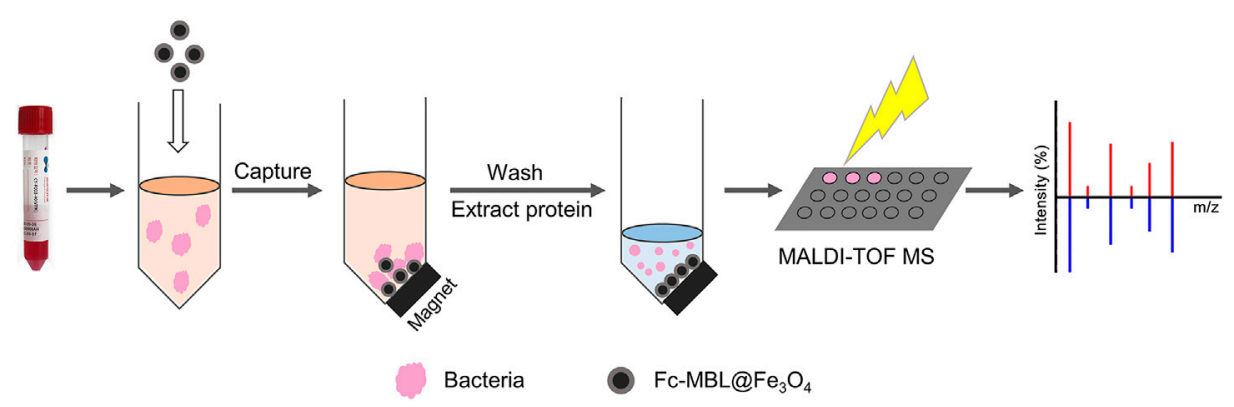

SCHEME 1 | Workflow for the identification of pathogens from the clinical liquid sample.

instructions. MicroCtrl 1.0 software was used to acquire the spectra and for real-time interpretation and identification; the raw spectra were processed by smoothing, baseline removal, and peak-picking, and the processed spectra were compared with the reference spectra in the database by using the pattern-matching algorithm of the software. The scores that ranged from 0.00 to 3.00 were calculated based on the correlation between the two spectra. According to the manufacturer, a score $>2.0$ is considered reliable in the species level, a score 1.7-2.0 indicates identification in the genus level, and a score $<1.7$ indicates unreliable result. Transmission electron microscopy (TEM) images were obtained by microscope JEOL JEM 2100 (Japan) at $200 \mathrm{kV}$.

\section{Sample Preparation and MNP Enrichment}

For verification of the method, the standard bacteria strains ( $S$. aureus, ATCC 25923; K. pneumoniae, CICC 21519) were inoculated on the TSA solid plate, and the single colonies were adjusted to certain concentrations by measuring the absorbance at $600 \mathrm{~nm}$ using UV-vis absorption spectroscopy. For the enrichment efficiency of $\mathrm{Fc}-\mathrm{MBL} @ \mathrm{Fe}_{3} \mathrm{O}_{4}, 1000$ or $100 \mathrm{CFUs}$ of $\mathrm{S}$. aureus and $10 \mu \mathrm{l}$ of Fc$\mathrm{MBL} @ \mathrm{Fe}_{3} \mathrm{O}_{4}$ solution $(10 \mathrm{mg} / \mathrm{ml})$ were added in $30 \mu \mathrm{l}$ Tris- $\mathrm{HCl}$ buffer $(0.1 \mathrm{mM}, \mathrm{pH} 7.4)$ containing $10 \mathrm{mM} \mathrm{CaCl}_{2}$ and $0.05 \%$ Tween-20 and incubated at $37^{\circ} \mathrm{C}$ for $15 \mathrm{~min}$ with shaking. After magnetic enrichment, the pellets were washed twice with $30 \mu \mathrm{l}$ of water. The supernatant was collected and cultured on the TSA solid media for $13 \mathrm{~h}$, together with the original solution and pellets. For the $S$. aureus assay, different amounts $\left(10^{8}, 10^{7}, 10^{6}\right.$, and $\left.10^{5} \mathrm{CFU}\right)$ of bacteria in $1 \mathrm{ml}$ of buffer solution were enriched by the similar method, wherein the pellets were washed with $100 \mu$ l of water. The $S$. aureus and K. pneumoniae in LB liquid media at the concentration of $10^{8} \mathrm{CFU} / \mathrm{ml}$ were carried out as follows; $300 \mu \mathrm{l}$ of buffer solution and $10 \mu \mathrm{l}$ of Fc-MBL@Fe $\mathrm{O}_{4}$ solution were added subsequently in $100 \mu \mathrm{l}$ of bacteria suspension, and the mixture was incubated at $37^{\circ} \mathrm{C}$ for $15 \mathrm{~min}$ with shaking. The pellets were washed twice with $100 \mu \mathrm{l}$ of water. The bacterial proteins were extracted from the Fc-MBL@ $\mathrm{Fe}_{3} \mathrm{O}_{4}$ by use of $5 \mu \mathrm{l}$ of $70 \%$ formic acid and $5 \mu \mathrm{l}$ of $\mathrm{ACN}$, and the extracted solution was subjected to MALDI-TOF MS analysis.

For the real case, a wound swab and $1 \mathrm{ml}$ of trauma fluid from the patient were collected in sterile containers and subjected to magnetic enrichment and MALDI-TOF MS profiling. The wound swab and fluid were both subcultured in $5 \mathrm{ml}$ of liquid LB medium at $37^{\circ} \mathrm{C}$ for $8 \mathrm{~h}$. For enrichment, $1 \mathrm{ml}$ of buffer solution was added to $300 \mu \mathrm{l}$ of subcultured liquid, and then, $20 \mu \mathrm{l}$ of $\mathrm{Fc}-\mathrm{MBL} @ \mathrm{Fe}_{3} \mathrm{O}_{4}$ solution was added. The obtained solution was incubated at $37^{\circ} \mathrm{C}$ for $15 \mathrm{~min}$ with shaking. After magnetic enrichment, the pellets were washed twice with $100 \mu \mathrm{l}$ of water. The bacterial proteins were extracted as above description. For the verification, the subcultured liquid samples were grown on the TSA solid medium for $24 \mathrm{~h}$, and the bacterial colonies were identified by MALDI-TOF MS.

\section{MALDI-TOF MS Analysis}

The bacterial protein solution $(1 \mu \mathrm{l})$ extracted from MNPs was deposited on a MALDI target plate. Then, CHCA matrix $(10 \mathrm{mg} /$ $\mathrm{ml}$ in $\mathrm{ACN} / \mathrm{H}_{2} \mathrm{O}(\mathrm{v} / \mathrm{v}=1 / 1)$ containing $\left.2 \% \mathrm{TFA}\right)$ was deposited on the sample spot after drying. For analysis of bacteria grown on the solid TSA medium, the standard extraction method was used (Matsuda et al., 2012). Briefly, a 1- $\mu$ l loop of bacteria was suspended in $300 \mu \mathrm{l} \mathrm{H}_{2} \mathrm{O}$, and $900 \mu \mathrm{l}$ ethanol was added. After vigorous vortex, the mixture was centrifuged at $12,000 \mathrm{rpm}$ for $5 \mathrm{~min}$. The supernatant was discarded, and $30 \mu \mathrm{l}$ of $70 \%$ formic acid was added to the pellets and thoroughly mixed. Next, $30 \mu \mathrm{l}$ of $\mathrm{ACN}$ was added, and the resulting solution was centrifuged again at $12,000 \mathrm{rpm}$ for $5 \mathrm{~min}$. One microliter of supernatant was deposited on the MALDI target plate and dried at room temperature. Finally, $1 \mu \mathrm{l}$ of CHCA matrix was placed on the sample spots and left to dry.

\section{Clinical Routine Pathogen Identification}

The clinical samples were inoculated on the Columbia blood agar, Sabourand's fungus agar, and anaerobic medium plate in a sterile manner and incubated in $35 \pm 2^{\circ} \mathrm{C}$ for $24-48 \mathrm{~h}$ in clinical microbiology laboratory. The bacteria grown on the solid media were subjected to Gram staining, and the isolates were identified using a VITEK2-Compact automatic bacterial identification instrument (Biomérieux) in accordance with the manufacturer's instructions.

\section{RESULTS AND DISCUSSION}

\section{Feasibility of the Proposed Method}

The workflow of the proposed method was illustrated in Scheme 1. The pathogens in liquid clinical samples or shortterm-cultured liquid samples were captured by Fc-MBL@ 
A

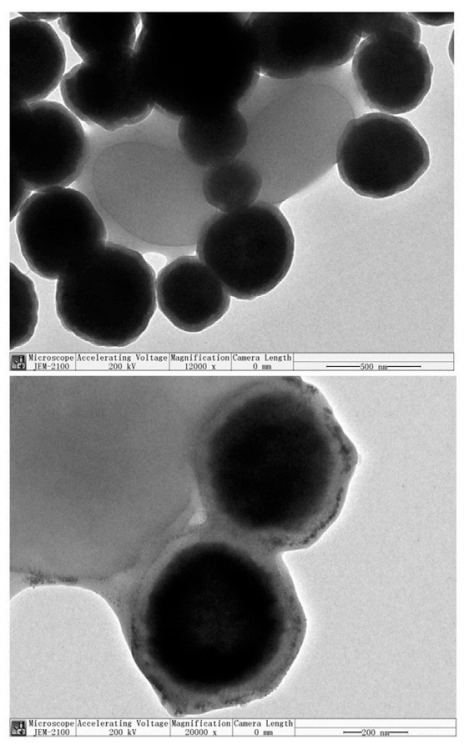

B Original Solution S. aureus@Fc-MBL@ $\mathrm{Fe}_{3} \mathrm{O}_{4} \quad$ Supernatant 1000 cells

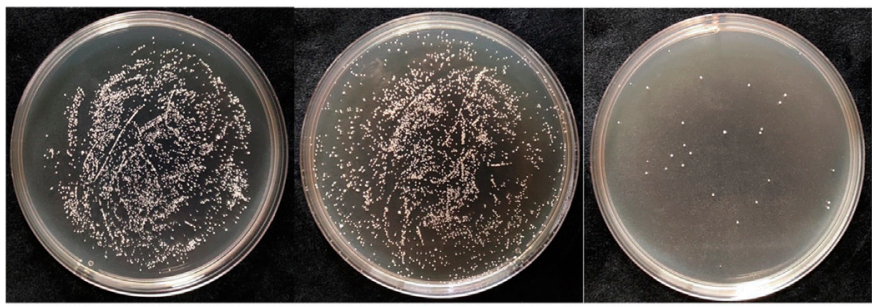

100 cells

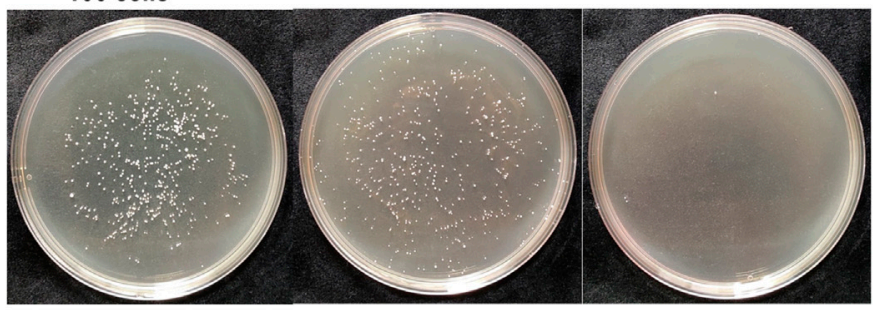

FIGURE 1 | (A) TEM images of S. aureus conjugated with FC-MBL@ $\mathrm{Fe}_{3} \mathrm{O}_{4}$. (B) Photographs of cultured plate of original solution, enriched pellets, and supernatant.

$\mathrm{Fe}_{3} \mathrm{O}_{4}$; the enriched bacteria were extracted by formic acid from Fc-MBL@Fe $\mathrm{O}_{4}$ and subjected to MALDI-TOF MS identification. Before application in real case, we investigated the feasibility of the method. A common pathogen in orthopedic infection, Staphylococcus aureus (S. aureus), was selected as model to verify the method. The synthesis and characterization of $\mathrm{Fc}-\mathrm{MBL} @ \mathrm{Fe}_{3} \mathrm{O}_{4}$ were presented in supporting information. The TEM images of Fc-MBL@ $\mathrm{Fe}_{3} \mathrm{O}_{4}$ binding to $S$. aureus are shown in Figure 1A, which indicated the binding capability of $\mathrm{Fc}-\mathrm{MBL} @ \mathrm{Fe}_{3} \mathrm{O}_{4}$ to $\mathrm{S}$. aureus. Next, the capture efficiency of $\mathrm{Fc}-\mathrm{MBL} @ \mathrm{Fe}_{3} \mathrm{O}_{4}$ was evaluated by the platecounting method. Briefly, the different amounts of $S$. aureus suspension were enriched by $\mathrm{Fc}-\mathrm{MBL} @ \mathrm{Fe}_{3} \mathrm{O}_{4}$; the bacteria in original solution, captured by $\mathrm{Fc}-\mathrm{MBL} @ \mathrm{Fe}_{3} \mathrm{O}_{4}$, and the supernatant were inoculated on the TSA plate in parallel, and the results are shown in Figure 1B. It can be seen that bacteria were almost captured completely by Fc-MBL@Fe $\mathrm{O}_{4}$. Then, the different amounts $\left(10^{8} / 10^{7} / 10^{6} / 10^{5} \mathrm{CFU}\right)$ of $S$. aureus in $1 \mathrm{ml}$ buffer solution were enriched by Fc-MBL@Fe $\mathrm{O}_{4}$ and identified by MALDI-TOF MS. As shown in Figure 2, the spectra of $\geq 10^{6} \mathrm{CFU}$ of bacteria in buffer enriched by Fc-MBL@Fe $\mathrm{O}_{4}$ show similar profiles with the standard spectrum of pure bacteria. It is should be noted that approximately $\sim 10^{5} \mathrm{CFU}$ are needed on the target plate for successful bacteria identification with MALDI-TOF MS (Segawa et al., 2014), which means the concentration of $10^{8} \mathrm{CFU} / \mathrm{ml}$ is needed, wherein $1 \mu \mathrm{l}$ of bacteria suspension is deposited on the target plate. In this method, the enriched pellets were eluted by $10 \mu \mathrm{l}$ solution ( $5 \mu \mathrm{l} 70 \%$ formic acid $+5 \mu \mathrm{l} \mathrm{ACN})$, and the $1 \mu \mathrm{l}$ of solution is deposited on the target plate. Thus, the results are rational that $10^{6} \mathrm{CFU}$ of bacteria in $1 \mathrm{ml}$ buffer solution could be detected successfully by the proposed method.

Furthermore, $S$. aureus and another bacteria Klebsiella pneumoniae (K. pneumoniae) were spiked in LB liquid media at
$10^{8} \mathrm{CFU} / \mathrm{ml}$ (the concentration of clinical positive cultures is $\left.\sim 10^{8} \mathrm{CFU} / \mathrm{ml}\right)$. The $100 \mu \mathrm{l}$ of liquid bacterial cultures were enriched by Fc-MBL@Fe $\mathrm{O}_{4}$ and analyzed by MALDI-TOF MS. The pure bacteria were tested by MALDI-TOF MS, and the obtained spectra were compared with those captured by Fc-MBL@Fe $\mathrm{O}_{4}$ from LB media. As shown in Figure 3, the spectra of captured bacteria (S. aureus and K. pneumoniae) from LB media show similar profiles to pure bacteria. For evaluation of reproducibility, the sample of $S$. aureus in LB broth was carried out in triplicate, and each sample was deposited at three spots; the obtained spectra all show matched profiles (Supplementary Figure S5). These results indicated the feasibility of the proposed method for rapid identification of bacteria in clinical bacterial liquid cultures.

\section{Identification of Bacteria in a Patient With Open Fracture}

Rapid and accurate identification of progressive bacteria colonizing orthopedic trauma, especially open fracture, is important for clinical diagnosis and treatment to avoid posttraumatic or postoperative infections. In the case presented here, the patient's leg suffered an open fracture on the coastal sea of China. Fc-MBL@Fe ${ }_{3} \mathrm{O}_{4}$ possesses a universal enrichment capacity for different pathogens, and MALDI-TOF MS can identify a wide range of pathogens, including bacteria and fungi, with high accuracy at both the genus and species level (97-99\% and $85-97 \%$, respectively) (Patel, 2013). Considering the special of this case, we attempt to use MALDI-TOF MS in coupling with Fc-MBL@Fe $\mathrm{O}_{4}$ enrichment for the identification of probable pathogens in this case. For analysis of clinical bacterial samples, a short-term subculture step is always needed since the amount of $\sim 10^{5} \mathrm{CFU}$ is requisite for MALDI-TOF MS identification. Herein, the wound swab and fluid were shortterm cultured in liquid LB media, and the liquid samples were analyzed by the proposed method. As a control, a sterile swab was 


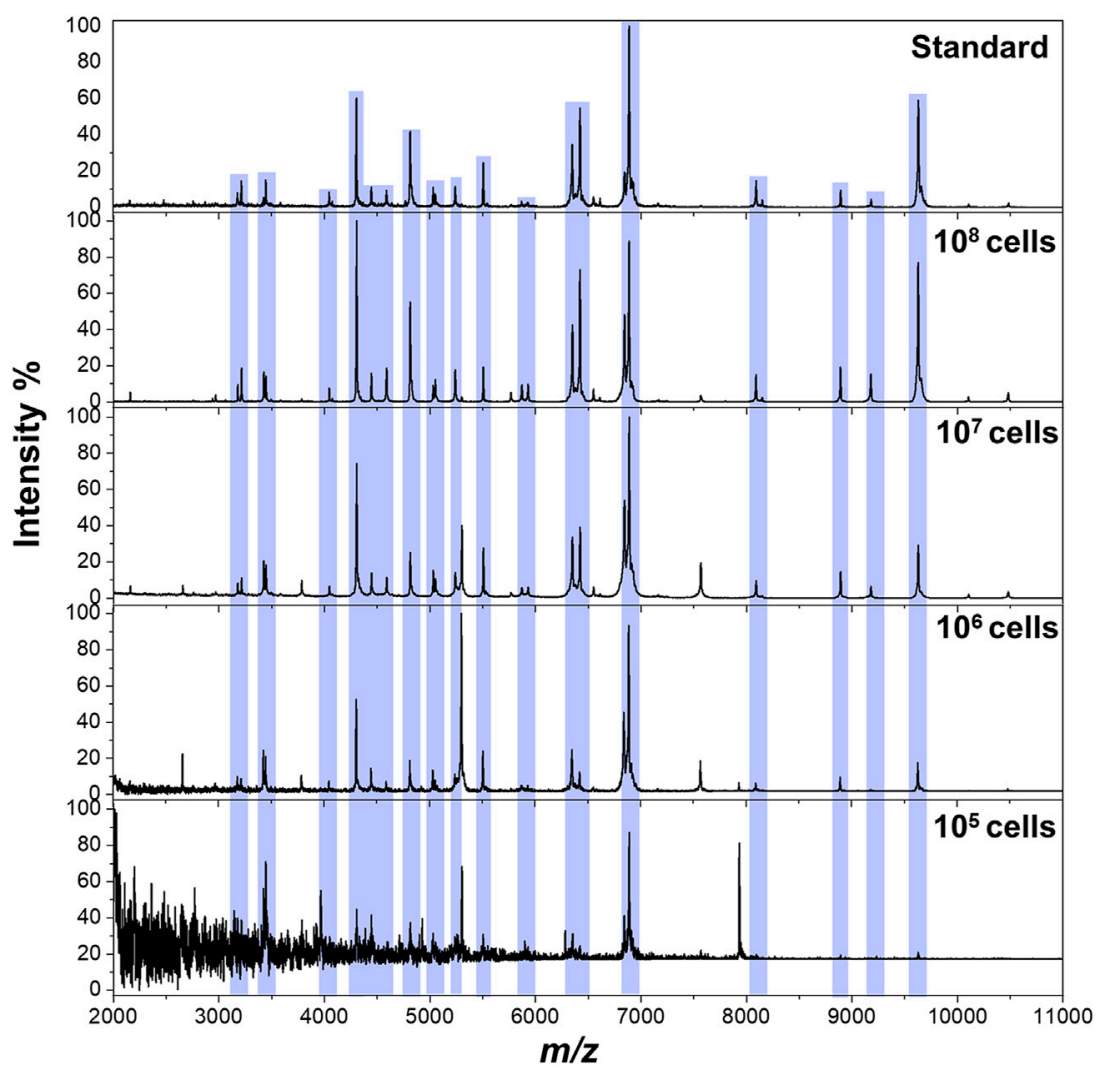

FIGURE 2|MALDI-TOF MS spectra of $S$. aureus obtained from pure solution (top) and enriched by Fc-MBL@Fe $\mathrm{O}_{4}$ from 1 ml buffer solution at different amounts.
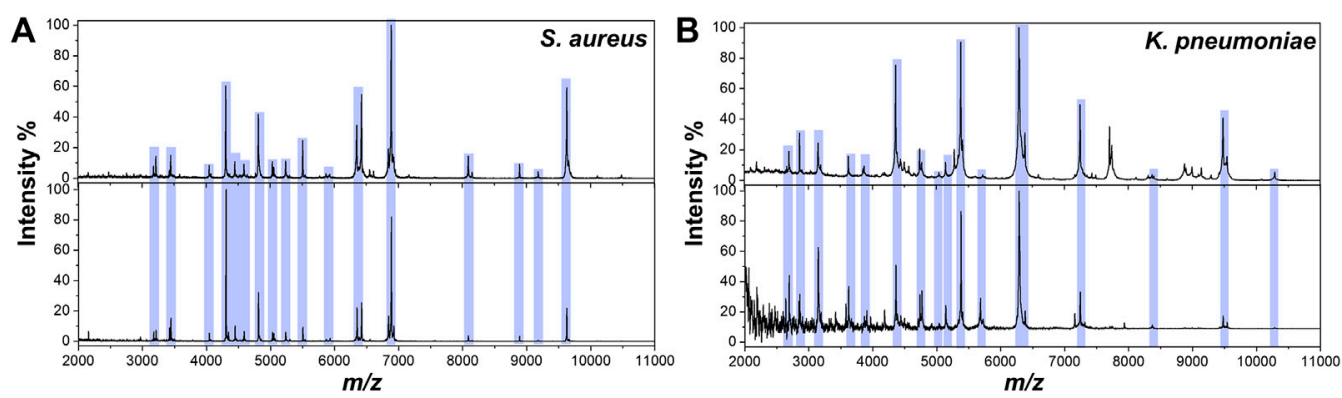

FIGURE 3 | MALDI-TOF MS spectra of (A) S. aureus and (B) K. pneumoniae obtained from pure solution (top) and enriched by Fc-MBL@Fe $\mathrm{O}_{4}$ from LB liquid media (bottom).

cultured in liquid LB media in parallel. Four sample spots were tested in parallel, and the representative mass spectrum is shown in Figure 4. The mass spectra of the bacteria in the wound swab matched Vibrio alginolyticus ( $V$. alginolyticus), a common pathogenic bacteria of numerous aquatic animals that is widely present in the sea, with an average score of 2.15 (Table 1). The fluid sample was also identified as $V$. alginolyticus, with an average score of 2.31 (Table 1). Thus, these scores indicated that the identification results were reliable at the species level. The LB media of the control group keep the clear liquid phase, and the identification results by the proposed method were unreliable (score $<1.7$ ), indicating that the control group is negative for bacteria.

\section{Verification of the Results}

To verify the results, short-term-cultured liquid samples continue to grow on a solid medium, and the isolates were analyzed by MALDI-TOF MS. The results were consistent with those obtained by magnetic enrichment coupled with MALDI-TOF MS (Table 1 and Supplementary Figure S6). 


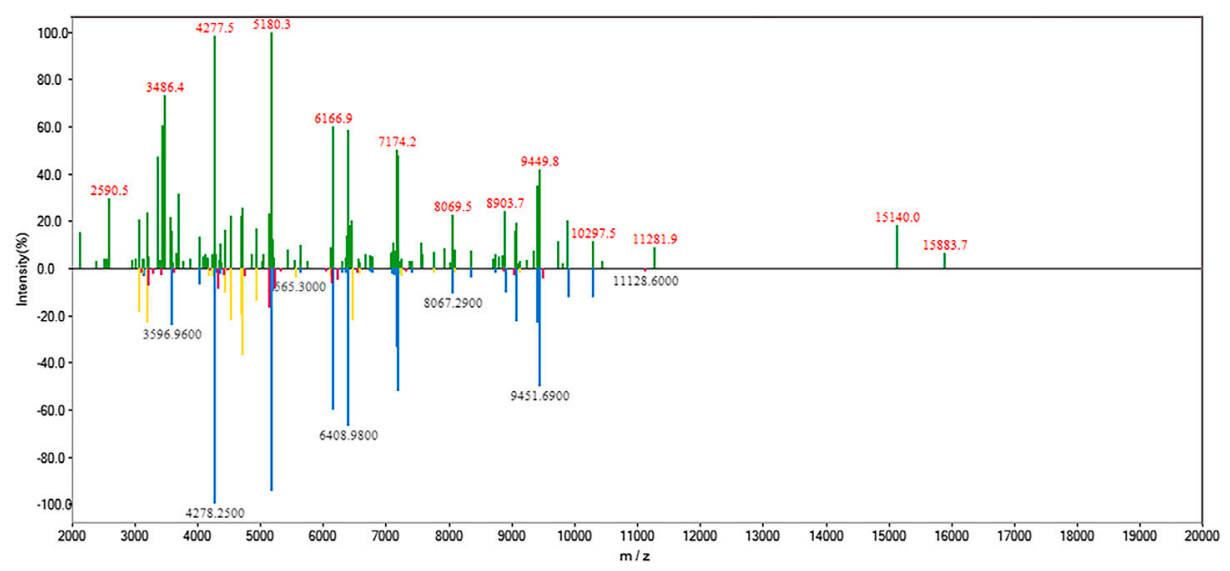

FIGURE 4 | MALDI-TOF MS spectrum of bacteria enriched by Fc-MBL@Fe ${ }_{3} \mathrm{O}_{4}$ (top) and matched spectrum of $V$. alginolyticus in the database (bottom). In the lower spectrum, the blue peaks represent matched peaks with high similarity, red peaks represent low similarity, and yellow peaks represent intermediate similarity.

TABLE 1 | MALDI-TOF MS identification of bacteria in a real case.

\begin{tabular}{lllllllll} 
Sample & \multicolumn{2}{c}{ The proposed method } & & & \multicolumn{3}{c}{ Solid culture-based method } \\
\cline { 2 - 3 } & Genus & Species & Score & & Genus & Species & Score \\
\hline Swab & Vibrio & alginolyticus & 2.14 & & Vibrio & alginolyticus & 2.41 \\
Swab & Vibrio & alginolyticus & 2.14 & & Vibrio & alginolyticus & 2.39 \\
Swab & Vibrio & alginolyticus & 2.12 & & Vibrio & alginolyticus & 2.27 \\
Swab & Vibrio & alginolyticus & 2.21 & & Vibrio & alginolyticus & 2.35 \\
Fluid & Vibrio & alginolyticus & 2.29 & & Vibrio & alginolyticus & 2.28 \\
Fluid & Vibrio & alginolyticus & 2.26 & & Vibrio & alginolyticus & 2.29 \\
Fluid & Vibrio & alginolyticus & 2.33 & & Vibrio & alginolyticus & 2.35 \\
Fluid & Vibrio & alginolyticus & 2.35 & & Vibrio & alginolyticus & 2.30
\end{tabular}

Furthermore, Gram staining showed that the bacteria were Gram-negative rods (Supplementary Figure S7), and the pathogen was identified as $V$. alginolyticus by the VITEK2Compact automatic bacterial identification system. $V$. alginolyticus, a type of Gram-negative opportunistic bacteria, infects both humans and aquatic animals (Xie et al., 2020). This infection is one of the main causes of aquaculture disease resulting in economic losses in mariculture in South China (Xie et al., 2005; Yu et al., 2018; Yu et al., 2019). Therefore, it was not surprising that $V$. alginolyticus was identified in this case. The whole process of the routine method required $>24 \mathrm{~h}$. The identification results from MALDI-TOF MS coupled with Fc-MBL@Fe $\mathrm{O}_{4}$ enrichment were in agreement with the conventional method and required only $\sim 9 \mathrm{~h}$.

\section{CONCLUSION}

In conclusion, direct pathogen identification from liquid-cultured clinical samples can be achieved by MALDI-TOF MS identification and appropriate pre-purification. Fc-MBL@Fe $\mathrm{O}_{4}$ could recognize and capture broad-spectrum microbes, and therefore, it is adaptable to combine with MALDI-TOF MS. In this study, we identified $V$. alginolyticus in a patient with an open fracture using MALDI-TOF
MS profiling coupled with Fc-MBL@Fe $\mathrm{O}_{4}$ enrichment. With extension of the MALDI microbial database, particularly for bacterial mixtures, magnetic enrichment coupled with MALDITOF MS has great potential for more clinical samples.

\section{DATA AVAILABILITY STATEMENT}

The original contributions presented in the study are included in the article/Supplementary Material, further inquiries can be directed to the corresponding authors.

\section{AUTHOR CONTRIBUTIONS}

JY: conceptualization, methodology, resources, and validation; WG: investigation, visualization, data curation, and validation; $\mathrm{DH}$ : resources, investigation, and validation; $\mathrm{CD}$ : investigation and conceptualization; LL: investigation, writing - original draft, and writing-reviewing and editing; TP: conceptualization and supervision; SY: conceptualization, supervision, funding acquisition, and project administration.

\section{FUNDING}

National Key Research and Development Program of China (No. 2018YFF0212501) and National Natural Science Foundation of China (No. 31470786). These two funds can pay for open-access publication fees.

\section{SUPPLEMENTARY MATERIAL}

The Supplementary Material for this article can be found online at: https://www.frontiersin.org/articles/10.3389/fchem.2021.672744/ full\#supplementary-material 


\section{REFERENCES}

Arnold, W. V., Shirtliff, M. E., and Stoodley, P. (2013). Bacterial Biofilms and Periprosthetic Infections. J. Bone Jt. Surg. Am. 95 (24), 2223-2229. doi:10.2106/ jbjs.m.00261

Backes, M., Spijkerman, I. J., de Muinck-Keizer, R.-J. O., Goslings, J. C., and Schepers, T. (2018). Determination of Pathogens in Postoperative Wound Infection after Surgically Reduced Calcaneal Fractures and Implications for Prophylaxis and Treatment. J. Foot Ankle Surg. 57 (1), 100-103. doi:10.1053/j. jfas.2017.08.016

Bicart-See, A., Rottman, M., Cartwright, M., Seiler, B., Gamini, N., Rodas, M., et al. (2016). Rapid Isolation of Staphylococcus aureus Pathogens from Infected Clinical Samples Using Magnetic Beads Coated with Fc-Mannose Binding Lectin. PLoS One 11 (6), e0156287. doi:10.1371/journal.pone. 0156287

Cheng, D., Yu, M., Fu, F., Han, W., Li, G., Xie, J., et al. (2016). Dual Recognition Strategy for Specific and Sensitive Detection of Bacteria Using Aptamer-Coated Magnetic Beads and Antibiotic-Capped Gold Nanoclusters. Anal. Chem. 88 (1), 820-825. doi:10.1021/acs.analchem.5b03320

Feng, B., Shi, H., Xu, F., Hu, F., He, J., Yang, H., et al. (2020). FTIR-assisted MALDI-TOF MS for the Identification and Typing of Bacteria. Analytica Chim. Acta 1111, 75-82. doi:10.1016/j.aca.2020.03.037

Firoozabadi, R., Alton, T., and Wenke, J. (2015). Novel Strategies for the Diagnosis of Posttraumatic Infections in Orthopaedic Trauma Patients. J. Am. Acad. Orthopaedic Surgeons 23 (7), 443-451. doi:10.5435/JAAOS-D-14-00174

Kang, J. H., Super, M., Yung, C. W., Cooper, R. M., Domansky, K., Graveline, A. R., et al. (2014). An Extracorporeal Blood-Cleansing Device for Sepsis Therapy. Nat. Med. 20 (10), 1211-1216. doi:10.1038/nm.3640

Liébana, S., Lermo, A., Campoy, S., Cortés, M. P., Alegret, S., and Pividori, M. I. (2009). Rapid Detection of Salmonella in Milk by Electrochemical MagnetoImmunosensing. Biosens. Bioelectron. 25 (2), 510-513. doi:10.1016/j.bios.2009. 07.022

Matsuda, N., Matsuda, M., Notake, S., Yokokawa, H., Kawamura, Y., Hiramatsu, K., et al. (2012). Evaluation of a Simple Protein Extraction Method for Species Identification of Clinically Relevant Staphylococci by Matrix-Assisted Laser Desorption Ionization-Time of Flight Mass Spectrometry. J. Clin. Microbiol. 50 (12), 3862-3866. doi:10.1128/JCM.01512-12

Morgenstern, M., Kühl, R., Eckardt, H., Acklin, Y., Stanic, B., Garcia, M., et al. (2018). Diagnostic Challenges and Future Perspectives in Fracture-Related Infection. Injury 49, S83-S90. doi:10.1016/S0020-1383(18)30310-3

Nemr, C. R., Smith, S. J., Liu, W., Mepham, A. H., Mohamadi, R. M., Labib, M., et al. (2019). Nanoparticle-Mediated Capture and Electrochemical Detection of Methicillin-ResistantStaphylococcus Aureus. Anal. Chem. 91 (4), 2847-2853. doi:10.1021/acs.analchem.8b04792

Nomura, F., Tsuchida, S., Murata, S., Satoh, M., and Matsushita, K. (2020). Mass Spectrometry-Based Microbiological Testing for Blood Stream Infection. Clin. Proteom 17, 14. doi:10.1186/s12014-020-09278-7

Papagiannopoulou, C., Parchen, R., Rubbens, P., and Waegeman, W. (2020). Fast Pathogen Identification Using Single-Cell Matrix-Assisted Laser Desorption/ Ionization-Aerosol Time-Of-Flight Mass Spectrometry Data and Deep Learning Methods. Anal. Chem. 92 (11), 7523-7531. doi:10.1021/acs. analchem.9b05806

Patel, R. (2013). MALDI-TOF Mass Spectrometry: Transformative Proteomics for Clinical Microbiology. Clin. Chem. 59 (2), 340-342. doi:10.1373/clinchem.2012. 183558

Patrulea, V., Borchard, G., and Jordan, O. (2020). An Update on Antimicrobial Peptides (AMPs) and Their Delivery Strategies for Wound Infections. Pharmaceutics 12 (9), 840. doi:10.3390/pharmaceutics12090840

Rhoads, D. D., Wolcott, R. D., Sun, Y., and Dowd, S. E. (2012). Comparison of Culture and Molecular Identification of Bacteria in Chronic Wounds. Ijms 13 (3), 2535-2550. doi:10.3390/ijms13032535

Segawa, S., Sawai, S., Murata, S., Nishimura, M., Beppu, M., Sogawa, K., et al. (2014). Direct Application of MALDI-TOF Mass Spectrometry to Cerebrospinal Fluid for Rapid Pathogen Identification in a Patient with Bacterial Meningitis. Clinica Chim. Acta 435, 59-61. doi:10.1016/j.cca.2014. 04.024
Singhal, N., Kumar, M., Kanaujia, P. K., and Virdi, J. S. (2015). MALDI-TOF Mass Spectrometry: an Emerging Technology for Microbial Identification and Diagnosis. Front. Microbiol. 6, 791. doi:10.3389/fmicb.2015.00791

Sun, J., Shi, H., Xue, Y., Cheng, W., Yu, M., Ding, C., et al. (2021). Releasing Bacteria from Functional Magnetic Beads Is Beneficial to MALDI-TOF MS Based Identification. Talanta 225, 121968. doi:10.1016/j.talanta.2020.121968

Takahashi, K., and Ezekowitz, R. A. B. (2005). The Role of the Mannose-Binding Lectin in Innate Immunity. Clin. Infect. Dis. 41 (Suppl. 7), S440-S444. doi:10. 1086/431987

Tuon, F. F., Cieslinski, J., Ono, A. F. M., Goto, F. L., Machinski, J. M., Mantovani, L. K., et al. (2019). Microbiological Profile and Susceptibility Pattern of Surgical Site Infections Related to Orthopaedic Trauma. Int. Orthopaedics (Sicot) 43 (6), 1309-1313. doi:10.1007/s00264-018-4076-7

Váradi, L., Luo, J. L., Hibbs, D. E., Perry, J. D., Anderson, R. J., Orenga, S., et al. (2017). Methods for the Detection and Identification of Pathogenic Bacteria: Past, Present, and Future. Chem. Soc. Rev. 46 (16), 4818-4832. doi:10.1039/c6cs00693k

Welker, M., Van Belkum, A., Girard, V., Charrier, J.-P., and Pincus, D. (2019). An Update on the Routine Application of MALDI-TOF MS in Clinical Microbiology. Expert Rev. Proteomics 16 (8), 695-710. doi:10.1080/ 14789450.2019.1645603

Woo, P. C. Y., Lau, S. K. P., Teng, J. L. L., Tse, H., and Yuen, K.-Y. (2008). Then and Now: Use of 16S rDNA Gene Sequencing for Bacterial Identification and Discovery of Novel Bacteria in Clinical Microbiology Laboratories. Clin. Microbiol. Infect. 14 (10), 908-934. doi:10.1111/j.1469-0691.2008.02070.x

Xie, Z.-Y., Hu, C.-Q., Chen, C., Zhang, L.-P., and Ren, C.-H. (2005). Investigation of Seven Vibrio Virulence Genes Among Vibrio Alginolyticus and Vibrio Parahaemolyticus Strains from the Coastal Mariculture Systems in Guangdong, China. Lett. Appl. Microbiol. 41 (2), 202-207. doi:10.1111/j.1472-765X.2005.01688.x

Xie, Z. Y., Gong, X. X., Xu, X. D., Mei, B., Xuan, X. Z., Long, H., et al. (2020). Identification of Vibrio Alginolyticus Virulent Strain-specific DNA Regions by Suppression Subtractive Hybridization and PCR. J. Appl. Microbiol. 129 (6), 1472-1485. doi:10.1111/jam.14739

Yi, J., Qin, Q., Wang, Y., Zhang, R., Bi, H., Yu, S., et al. (2018). Identification of Pathogenic Bacteria in Human Blood Using IgG-Modified Fe3O4 Magnetic Beads as a Sorbent and MALDI-TOF MS for Profiling. Microchim Acta 185 (12), 542. doi:10.1007/s00604-018-3074-1

Yu, Q., Li, F., Wang, Y., Qin, X., Chen, X., Wu, L., et al. (2018). Isolation, Identification and Pathogenicity of Vibrio Alginolyticus from Marine Cultured Trachinotus Ovatus in Beibu Gulf,Guang Xi. Guangxi Sci. 25, 68-73. doi:10.13656/j.cnki.gxkx.20180208.001

Yu, Q., Liu, M., Xiao, H., Wu, S., Qin, X., Ke, K., et al. (2019). Development of Novel Aptamer-based Enzyme-linked Apta-sorbent Assay (ELASA) for Rapid Detection of Mariculture Pathogen Vibrio Alginolyticus. J. Fish. Dis. 42 (11), 1523-1529. doi:10.1111/jfd.13066

Yun, H. C., Murray, C. K., Nelson, K. J., and Bosse, M. J. (2016). Infection after Orthopaedic Trauma: Prevention and Treatment. J. Orthop. 30, S21-S26. doi:10.1097/bot.0000000000000667

Zboromyrska, Y., Rubio, E., Alejo, I., Vergara, A., Mons, A., Campo, I., et al. (2016). Development of a New Protocol for Rapid Bacterial Identification and Susceptibility Testing Directly from Urine Samples. Clin. Microbiol. Infect. 22, e1-561.e1-6. doi:10.1016/j.cmi.2016.01.025

Zhu, Y., Qiao, L., Prudent, M., Bondarenko, A., Gasilova, N., Möller, S. B., et al. (2016). Sensitive and Fast Identification of Bacteria in Blood Samples by Immunoaffinity Mass Spectrometry for Quick BSI Diagnosis. Chem. Sci. 7 (5), 2987-2995. doi:10.1039/c5sc04919a

Conflict of Interest: The authors declare that the research was conducted in the absence of any commercial or financial relationships that could be construed as a potential conflict of interest.

Copyright (C) 2021 Ying, Gao, Huang, Ding, Ling, Pan and Yu. This is an open-access article distributed under the terms of the Creative Commons Attribution License (CC $B Y)$. The use, distribution or reproduction in other forums is permitted, provided the original author(s) and the copyright owner(s) are credited and that the original publication in this journal is cited, in accordance with accepted academic practice. No use, distribution or reproduction is permitted which does not comply with these terms. 